U.A.R. J. Anim. Prod., Vol. 10, No. 1, pp. 55-63 (1970).

\title{
THE EFFECT OF SELECTION FOR HIGH BODY WEIGHT AND HIGH NUMBER ON GENETIC AND $\because$ PHENOTYPIC VARIATION IN TWO STRAINS OF FAYOUMI CHICKENS
}

\section{By}

\author{
M. A. EL-Hossari *
}

Two selection experiments were carried out on two strains of Fayoum chicken, one to inerease body weight at 8 weeks of age in seven generations, and the other to increase egg number to the firet of January tions, and the other to increase egg number to the five generations. The phenotypic and the genetic variation before and after selection were stadiod.

In the first strain, selection for high body weight decreased the phenotypic variation in body weight measurements; at 4 wesks, 8 week, and at 12 weeks of age, while the genetie varisnce of these traits had a tendency to be increased. Similsrly in the second atrain, selection for high egg number deareased the phenotypic variation in egg number measurements; to 21 weeks after the first egg, to 12 monthe egg lum to Ianuary the firat and to June the first, while the genetio variance were increased.

The increase in genetic variance might be attributed to the trans. formation of potential into free variability due to additive selction.

It is generally assumed that additive selection for s particular charaoter leads to more uniformity in performance. This is due to the exhaustion of the genetic variability and hence, the phenotypic variability may be decreased. genetic varia) however, reported that selection might increase genetic variability. He suggested that gelection does not create such new genetic variation, but may aid in the transformation of potential into free variation. "Selection may utilize the variability already present in the population by changing gene frequencies and by creating new genotypes from the genes already present through a re-8orting of whole ohromosomes and through picking a more desirable oross-over types within a chromosome pair".

Mather and Harrison (1949), on Drosophila, reported that genetio variance was incressed in the selected oharacter due to the release of potential variability.

The phenotypic variability of a population may be changed according to the degree of heterozygostiy, less variance is in heterozygotes than in homozygotes (Wigan, 1944 and Prevesti, 1953). This is because the heterozygotes are less susceptible to uncontrolled exvironments than the homozygotcs (the phenotypic extremes).

- Animal Produotion Dopt. Ministry of Agric. Cairo, U.A.R. 
Selection is towards the fixation of desirable genes. If a chsracter in a random population is controlled by a desirable allele (A), the genotype frequency will be (AA: Aa : aa). Selection increases the frequency of (A) in the population. That is to say, it increases the genotypes (AA) and (Aa) and decreases the genotype (aa). In this case, if the increase is more in genotypes (Aa) "The heterozygous advantage" than in the gonotypes (AA) "the homozygotes", the phenotypic variance is expected to be decreased. On the other hand, if the increase is more in genotypes (AA) "additive effect" than in genotypes (Aa) and the rate of increase is equal to the rate of decrease in genotypes (aa), the phenotypic variance may be unchanged. Since the chance of releasing potential variability is more in heterozygotes than in homozygotes (Mather and Harrison, 1949), the genetic variability may be increased, though the phenotypic variability has been decresed.

Therefore, the effect of seleotion on genetic and phenotypic variance depends on genotype frequeney and on the type of genes which govern the selected charceters in a particular population.

Some workers found that afcer many generations of selestion for a certain trait, the degree of uniformity of this particular traic was not satisfactory and less than expected theoretically. On chickens, Maloncy (1963) found that selection for high body weight at 12 weeks of as: decreased the phenotypic varignee but not as desired. This is also supported by Ideta and Siegel (1966).

The relationship between genetic and phenotypioc variation and the roles of their behaviours during selection procedure are still a matter of argument. More explanation in poul.ry are needed to clarify such phenomena. In this paper, the gene:ic and phenotypic variance before and after selection were discussed in two strains of Fayoumi chickens; one selected for high body weight and the other for high egg number.

\section{Material and Method}

Two strains were established by selection from a Fayoumi flock. Individual selectin was carried out in the "growth strain" to inerease body weight at eightweeks of age, and full-sibs family selection was practiced in the "production strain" to increase egg numbor to the first of January. Records were collected over seven generations of selection in the former strain and five generations in the latter.

A randombred control (unselected population) was also established s nce the beginng of selection experiments and its performance was recorded for comparism and to estimate the genetic gains more accurately.

Before selection, a random sample of 650 day- old chicks was taken from a Fayoumi flock in Fayoum Poultry Experimental station. The chickes were weighed every four weeks to twelve weeks of age. The performance of 1258 selected chicks were recorded in the second generation. The data for analysis was taken from 496 pedigree pullets mated rondomly.

At the end of selection 1402 day - old ehicks taken from the growth starain, were weighed every four weeks to twelve weeks of age. The flocks' size from which the rusults were obtained after selecton were about, 600 pullets for tho 
growth strain, 800 pullets for theuction strain and 500 pullets for therandombred control.

The average selection differential per generation for body weight at eight weeks of age during the selection periods was 100.8 grams, and for egg number to the first of January was 17.33 egggs.

The traits studied:

Simbol

$$
\text { Trait }
$$

4. WK. Body weight at 4 weeks of age.

8. WK. Body weight at 8 weeks of age.

12. WR. Body weight at 12 woeks of age.

S.M. Age at sexual maturity (age at first egg)

M.B.W. Body weight at sexual maturity

M.E.W. $\quad \mathrm{Egg}$ woight at sexual maturity

12 E.W. Egg weight at 12 months of age.

Pause 5. Number of unproductive days during five months (December to Aprel).

$P_{1} \quad$ Egg number to 21 weeks after the first egg.

$\mathrm{P}_{2} \quad$ Egg umber to 12 months of age.

$\mathbf{P}_{3} \quad$ Egg number to the first of January.

$\mathbf{P}_{4} \quad$ Egg number to the first of June.

\section{Method of Analysis}

(a) The phenotypic variance was expressed in two ways, before and sfter the selection experiments :-

1. The standard deviation of the population (S.D.)

2. The coefficient of variance percentage. (C.V.)

(b) The genetic variance was measured as, the heritability $\times$ Phenotypic variance, of the trait before and after selection. $\left(\sigma^{1} G=h^{2} \times \sigma_{p}^{2}\right)$.

The heritabilities were estimated by these ways:-

I. Analysis of variance (full-sib correlation). Before analysis, the data were adjusted to their hatch mean (El-Hossari 1966).

2. The realised $\mathrm{h}^{2}$ (Facloner 1960):

(a) The reslised $h^{2}$ for the selected trait $\left(h^{2}{ }_{x}\right)=\frac{\Delta \ddot{G}}{i}$ where $\Delta \vec{G}$ is the gentic gain per generatin for the selected trait, and is the selection differential per generation. 
(b) The realised $h^{2}$ for correlated trait. ( $h^{2}$ ) for individual selection in the growth strain

$$
\mathrm{h}^{2} y=\left(\frac{\Delta \overline{\mathrm{G}} \mathrm{y}}{\Delta \overline{\mathrm{G}}_{\mathrm{x}}}\right)^{2} \cdot \frac{\sigma^{2} \mathrm{x}}{\sigma^{2} \mathrm{y}} \cdot \frac{\mathrm{h}^{2} \mathrm{x}}{\mathrm{r}_{\mathrm{G}}}
$$

for faimiy selection in the production strain

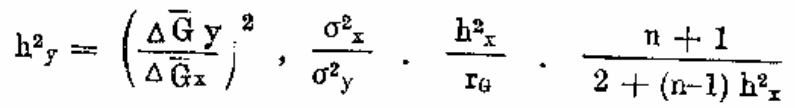

Where $\Delta \vec{G}_{x}$ represents the genetic gain in the selected trait $(X)$ $\Delta \bar{G}_{y}$ is the genetio change in the correlated trait not directly
selected $(y)$,

$h^{2}{ }_{x}$ and $h^{2}{ }_{y}$ are the hertiabilities of traits $(X)$ and $(y$,

$\sigma^{2}{ }_{x}$ and $\sigma^{2}{ }_{y}$ are the phenotypic variance,

$r_{0}$ is the genetic correlation between trait $X$ and $Y$ and is the average size of dam family.

The genetio correlation as estimated by using analysis of covariance (El-Hossari 1961). The standard errors of the heritabilities and of the genetic correlations were derived according to the method shown by Falconer (1960).

The genetic gain for the direct responses $\left(\Delta{\overrightarrow{v_{s}}}_{s}\right)$ and for the oorrelated responses $\left(\Delta \bar{G}_{y^{\prime}}\right)$ were obtained from the difference between the performance of the randombred control $(R)$ and the performance of the strain after the period
of selection.

\section{Results and Discussion}

Takle I. represents the phenotypic variance measured as standard deviation and as coefficient of variance percentage for the different trait studied in the original flock ( $\mathrm{F}_{\mathrm{o}}$ ) before selection, in the randombred control (R), in the growth strain (strain $G$ ) and in the production strain (strain $P$ ) at the end of the selection experiments.

It is obvious that selection for 8 - week body weight in the grow strain has decreased the phenotypic variance in early body weights. There is consistent difference between the coefficients of variation of the growth strain and the tandombred control, as well as the original flock. However, the difference does not appear to be important in the egg production traits except in pinse duration and in egg weight at sexual maturity which show selection for in variability. Maloney et al (1963) also found that selection for high body weight at 12 weeks of age for ten generations oaused be cocficient of variance in body woight to become smaller.

The penotypic variance in growth were decreased in the later years and at the same time gain, due to direct or correlated responses to selection were increase and some of the observed responses exceeded the expected values

U.A.R. J. Anim. Prod., 10, No. 1 (1970). 


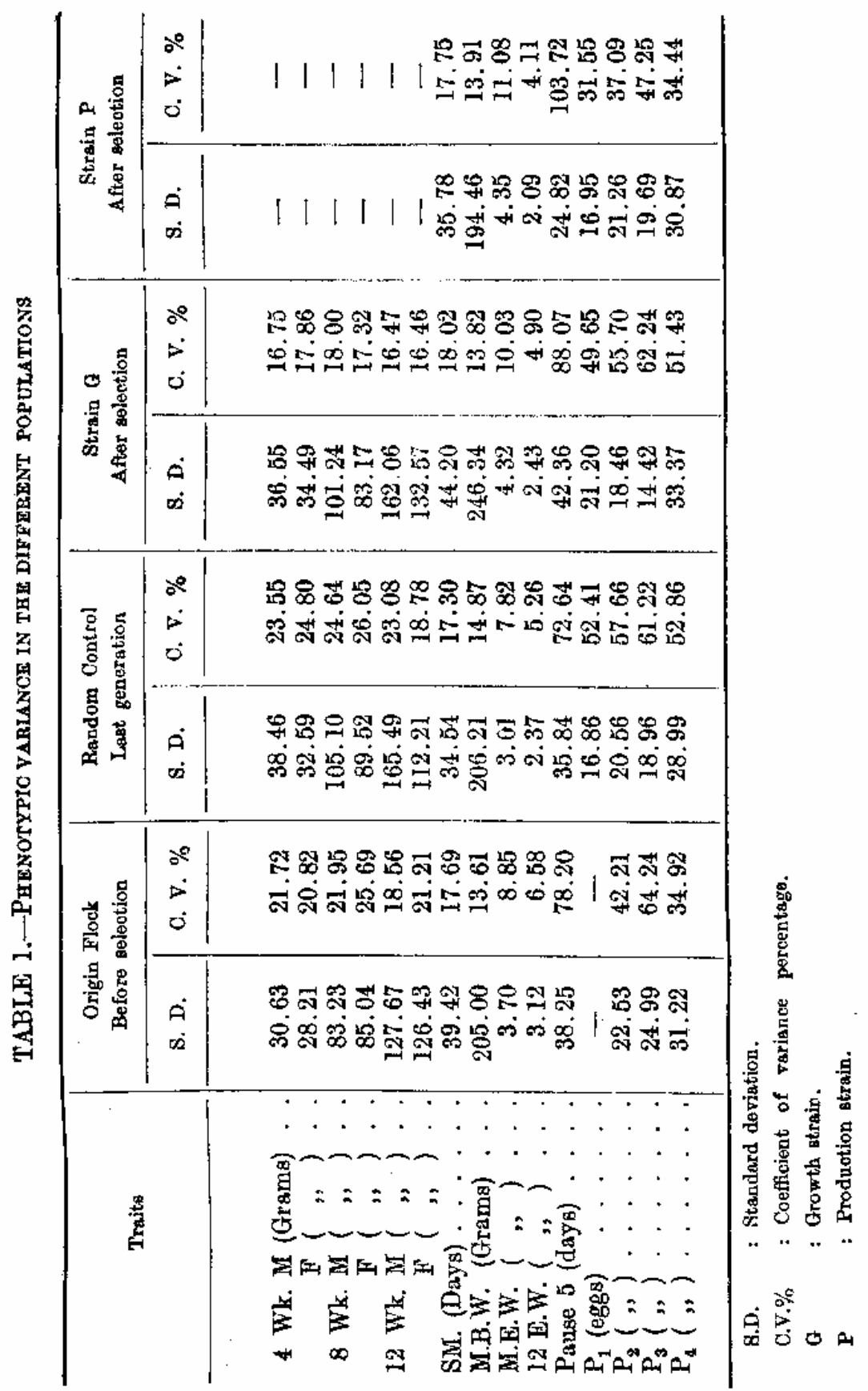

J.A.R. J. Anim. Prod, 10, No. 1 (1870). 
(Ragab and Hossrai 1969). The decrease in varianoe was more marked in female than in male progeny for body weight at 8 weeks of age, the selection criterion used, while the observed gain was markedly larger than expected particularly in the last two generations for female progeny. This Berge (1959) whort the work of Hammond and Birds (1942) and Backer and phenotypic varaince.

With respect to selection for ege number in the production strain tent significant decrease in phenotypic variablitiy was observed after five gencrations of selection, while considerable duration and in egg weight at maturity. sexual maturity and body weight arity. However, variability in age at

Table 2 shows the, estinates of the heritabilities of the different traits

TABLE 2. -HERITABILITY ESTIMATES BEFORE AND AFTER SGLECTION

\begin{tabular}{|c|c|c|c|c|c|}
\hline \multirow{2}{*}{ Traits } & \multirow{2}{*}{$\mid \begin{array}{c}h^{2} \text { of the flock } \\
\text { before selection } \\
\text { (Fo) }\end{array}$} & \multicolumn{2}{|c|}{$\begin{array}{c}\mathrm{h}^{2} \text { after aqlection } \\
\text { (analysis of variance) }\end{array}$} & \multicolumn{2}{|c|}{ Realized ha } \\
\hline & & Strain $G$ & Strain P & Str, $G$ & Str. P \\
\hline 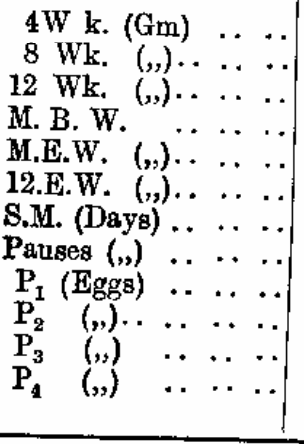 & $\begin{array}{l}.390 \pm .061 \\
.388 \pm .061 \\
.434 \pm .062 \\
.403 \pm .086 \\
.484 \pm .088 \\
.458 \pm .088 \\
.309 \pm .084 \\
.254 \pm .082 \\
.151 \pm .078 \\
.245 \pm .081 \\
.233 \pm .091 \\
.200 \pm .080\end{array}$ & $\begin{array}{l}.619 \pm .083 \\
.405 \pm .083 \\
.417 \pm .083 \\
.552 \pm .077 \\
.340 \pm 0.71 \\
.332 \pm .085 \\
.444 \pm .089 \\
.446 \pm .089 \\
.210 \pm .061\end{array}$ & $\begin{array}{c}- \\
\overline{-} \\
.356 \pm .062 \\
.286 \pm .051 \\
\overline{ \pm} \\
.320 \pm .062 \\
.303 \pm .061 \\
.343 \pm .062 \\
.289 \pm .059 \\
.283 \pm .059\end{array}$ & \begin{tabular}{|c|}
.446 \\
.438 \\
.428 \\
.379 \\
.374 \\
-211 \\
.21 \\
.323 \\
.706 \\
.233
\end{tabular} & $\begin{array}{l}- \\
- \\
.222 \\
.252 \\
.280 \\
.255 \\
.543 \\
.419 \\
.276 \\
.402 \\
.329\end{array}$ \\
\hline
\end{tabular}

Table 3 shows the genetic gain in both strains due to selection. It also indicates the significant differences of the genetic and phenotypio variance
abefore and after selection.

It can be seen that, in the growth strain, the genetio varianee for body weight measuroments ( 4 weeks, 8 weeks, 12 weeks and M.B.W.) were not decreased after selection for high body weight at 8 weeks of age (the difference between the $\mathbf{h}^{2}$ estimates of Fo and strain $\mathrm{G}$ are insignificant). Actually variance estimates of to be increased. Similarly in the production strain the due to selection for high egg production measurements were not decreased $P_{1}, P_{3}$ and $P$. M.R. I. Anim. Prod., 10, No. 1 (1970). 
Robertson and Reeve (1952) found also that the genetio variation was increased when they selected for wing and thorax length on Drosophila melanogaster. They suggested that the selected genes which could be fixed might have their effect on the character magnified the selection of modifying genes. This provides one possible explanation for rise in variance of a character after many genorations of selection.

It can be also seen that the genetic variation in age at suxual maturity was not effected by selection in both selection experiments (strain $\mathbf{G}$ and $\mathbf{P}$ ).

There was adecrease in $\mathbf{h}^{2}$ estimates of body weight and egg weight measurements the production strain, while $h^{2}$ estimates were increaed in egg number messurements $\left(\mathrm{P}_{1}\right.$ and $\left.\mathrm{P}_{2}\right)$ in the growth strain. Random drift could be a possible explanation for these observations.

Therefore, selection for 8-weeks body weight in the growth strain decreased the phenotypic variance in body weight measurements (4 WK, 8 WK and 12 WK.), while the genetio variance of these traits had a tendency to be inoreased. Similarly in the production strain, selection for egg number decreased the phcnotypic variance in egg number measurements, while the genetio variances were increased.

TABLE 3.-GENETIC GAINS AND SHLKOTION EPPEOT ON FHENOTYPIC AKD GENETIC VARIANCE

\begin{tabular}{|c|c|c|c|c|c|c|c|c|c|}
\hline \multirow{2}{*}{ Traite } & \multicolumn{2}{|c|}{ Genetio Gains } & \multicolumn{3}{|c|}{ "Gentio varianoe $\left(\sigma^{2} G\right)$} & \multicolumn{2}{|c|}{$\sigma^{*} G$} & \multicolumn{2}{|c|}{$0^{2 P}$} \\
\hline & St. G & St. $\mathbf{p}$ & $F_{0}$ & St. G. & Bt. P. & $\underset{Q}{\text { St. }}$ & $\begin{array}{l}\text { St. } \\
\text { P }\end{array}$ & $\begin{array}{l}\text { St. } \\
\mathbf{G}\end{array}$ & $\begin{array}{l}\text { St. } \\
\text { P }\end{array}$ \\
\hline $\begin{array}{c}\text { 4Wk. (Gm) } \\
\text { 8Wk. (,) } \\
\text { l2Wk. (,) } \\
\text { M.B.W. (,) } \\
\text { M.E.W (,) } \\
\text { 12E.W. (,) } \\
\text { S.M. (Days) } \\
\text { Pauses (,) } \\
\mathrm{P}_{1}(,) \\
\mathrm{P}_{2}(,) \\
\mathrm{P}_{3}(,) \\
\mathrm{P}_{4}(,)\end{array}$ & $\begin{array}{c}58.30 \\
136.90 \\
235.01 \\
396.40 \\
4.58 \\
4.54 \\
45.79 \\
-1.23 \\
10.53 \\
-2.52 \\
-7.80 \\
10.05\end{array}$ & \begin{tabular}{|l|}
$\cdots$ \\
$\cdots$ \\
$\because 11.50$ \\
0.78 \\
1.13 \\
1.93 \\
-25.41 \\
21.65 \\
21.66 \\
10.70 \\
34.80
\end{tabular} & \begin{tabular}{|c|}
337.10 \\
2746.86 \\
7005.50 \\
16936.08 \\
6.63 \\
4.60 \\
480.17 \\
371.62 \\
76.68 \\
124.36 \\
145.51 \\
194.94
\end{tabular} & $\begin{array}{c}654.07 \\
3442.84 \\
9050.23 \\
34386.36 \\
5.34 \\
\cdots . \\
448.61 \\
\ldots . \\
199.55 \\
160.33 \\
\ldots . \\
233.85\end{array}$ & $\begin{array}{c}\cdots \\
\cdots \\
\cdots \\
13462.03 \\
5.41 \\
4.73 \\
409.67 \\
186.66 \\
93.44 \\
130.63 \\
189.12 \\
269.69\end{array}$ & $\begin{array}{l}+ \\
= \\
+ \\
+ \\
+ \\
\cdots \\
\Rightarrow \\
\ddot{+} \\
+ \\
\cdots \\
=\end{array}$ & $\begin{array}{l}\cdots \\
\cdots \\
- \\
= \\
= \\
- \\
+ \\
= \\
+ \\
+\end{array}$ & $\begin{array}{l}- \\
- \\
= \\
+ \\
= \\
= \\
+ \\
= \\
= \\
=\end{array}$ & $\begin{array}{l}\cdots \\
\cdots \\
= \\
+ \\
= \\
+ \\
+ \\
- \\
-\end{array}$ \\
\hline
\end{tabular}

- : Genetic variance $(\sigma \mathrm{G})=$ Heritability $\left(h^{2}\right) \times$ Phenotypic variance $\left(\sigma^{2} P\right)$.

+ : The rairance is larger after selection than before gelection.

- The varianoe is amoller after aelection than before eelection.

- No significant difference between the verisnce.

U.A.R. J. Anim. Prod., 10, No. 1 (1970). 
The decrease of the phenotypic variation in both seleotion experimenta might be due to more uniformity in performance as a result of selection as discussed above. The inorease of the genetic variation is generally attributed to two reasons: 1 . the presence of non - additive effect, 2, the tranaformation of potential to free variation.

The first reason, however, could be rejected in our case because there was no signifioant differencelbetween the observed and the expeced responses to eleotion in both atrains (Ragab and Hossari 1969).

It wonld be thenooncluded that, although the phenotypio variability was aignificantly deoreased due to selection for high body weight and for high egg number, the genetic variation was not affected snd shows tendenoy to be increased partioularly in egg number oharacters.

These evidences indicate that sleection has relessed genetio variation, and further generations of additive aelection on these two Fayoumi atrains are suggested for more uniformity and for more imporvement in performance.

\section{Acknow ledgement}

The auther wishes to express his thanks to Prof. M. T. Ragab, and to Dr. A. A. El-Itriby for their help in this study.

\section{REFERENCES}

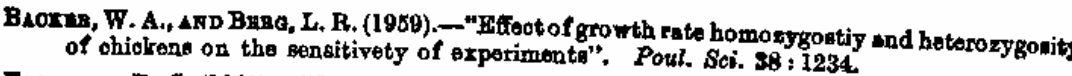
Furoorws, D. S. (1960).-"Introduction to Quantilative Geneties'. Oliver and Boya Ltd. Gront
Britain.

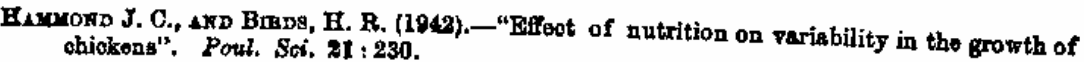

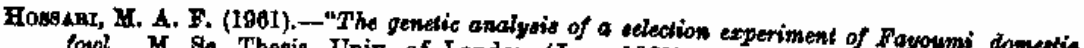
fovl., M. So. Theris, Univ, of London (June 1961).

- (1908). - "The Fayoumi Domewtio Fowl : (C) the heritability of ame of the economis traits. Agrie. Res. Rev. Cairo, Vol. $4 ; 141$.

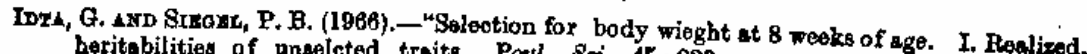
heritabilities of unseleted traits. Poul. Sci. $\mathbf{1 5 : 0 2 3 .}$

Lanxas, I. M. (1950).- "Population genetics and animal improvemens". Cambridgo Unit. Proas

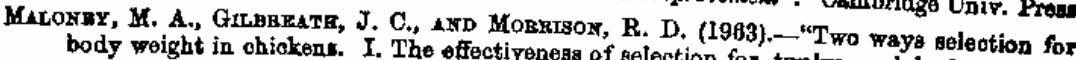
Pout. Bci. 25 : 326 . MateFB, K, exD HaBnisor, B. J. (1949), "The maniford effect of selection". Eeredity, $\$$ t
I, 131.

Parroatr, A. (1952),_-_"Variabilidad gonica en una papblucion natural de Drosophila subobsoura,"
Genetica Iberica, $4: 95$.

RAaAB, M. T., aND Hossari, M. A. (1969).-- "Aelection for high egg yield and for rapid gronot in a closed flock of Fayoumi fowl". (Under pross).

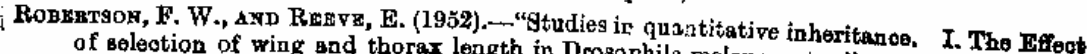
of Belection of wing and thorax length in Drosophila melanogaster." J. Genet. The Fffect

Wrous, Z. G. (9144).-."Balanoe and potence in natural populations". Ibid: $46: 150$.

U.A.R, J. Anim. Prod., 10, No. 1 (1970). 


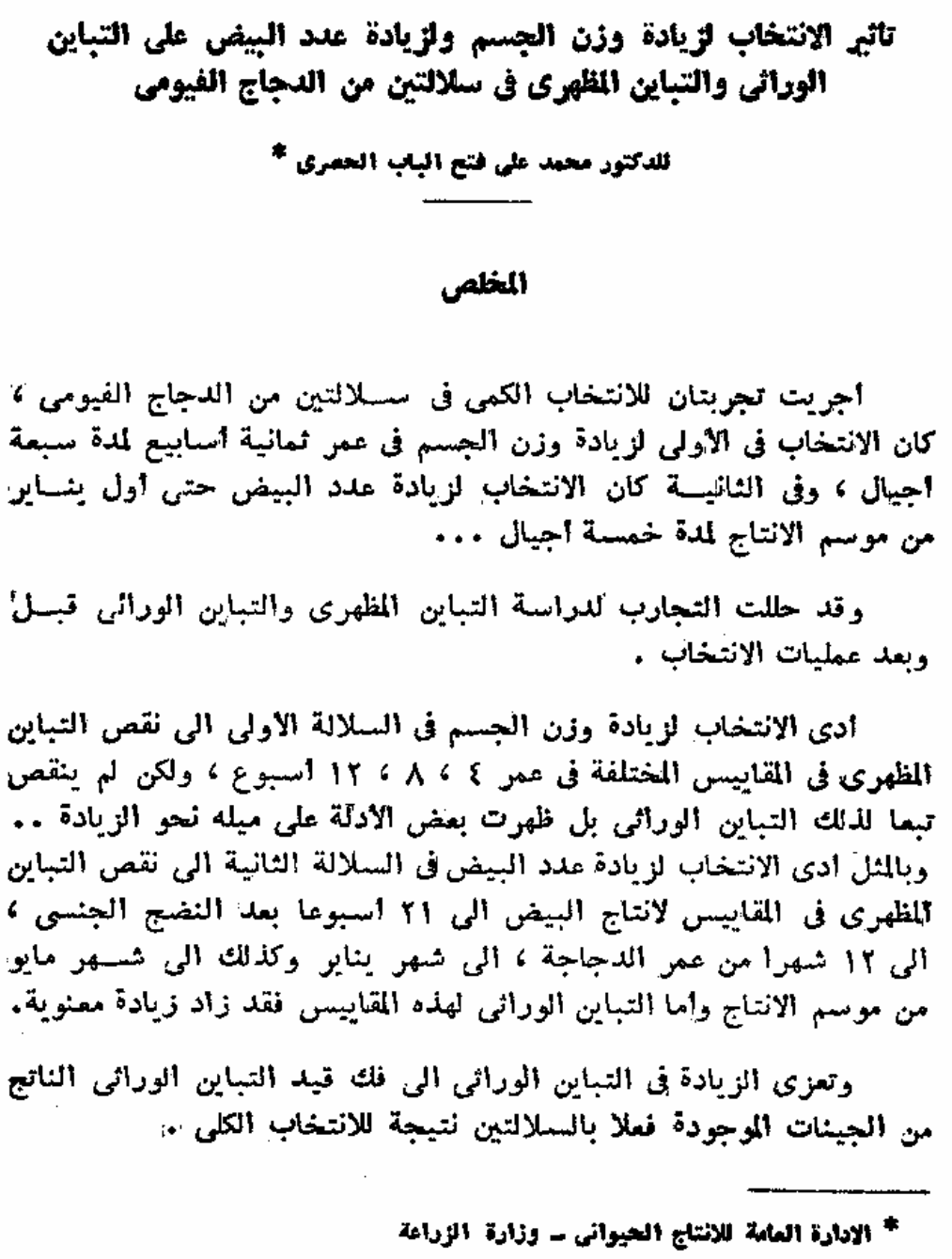

